\title{
Sox11 is an Activity-Regulated Gene with Dentate-Gyrus-Specific Expression Upon General Neural Activation
}

\author{
Julia von Wittgenstein ${ }^{1,2}$, Fang Zheng ${ }^{3}$, Marie-Theres Wittmann ${ }^{1,4}$, \\ Elli-Anna Balta ${ }^{1}$, Fulvia Ferrazzi ${ }^{4}$, Iris Schäffner ${ }^{1}$, Benjamin M. Häberle ${ }^{1}$, \\ Maria J. Valero-Aracama ${ }^{3}$, Muriel Koehl ${ }^{5}$, Carlos J. Miranda ${ }^{6}$, \\ Brian K. Kaspar ${ }^{6}$, Arif B. Ekici ${ }^{4}$, André Reis ${ }^{4}$, Djoher Nora Abrous ${ }^{5}$, \\ Christian Alzheimer ${ }^{3}$ and D. Chichung Lie ${ }^{1}$
}

${ }^{1}$ Institute of Biochemistry, Emil Fischer Center, Friedrich-Alexander-Universität Erlangen-Nürnberg, 91054 Erlangen, Germany, ${ }^{2}$ Department of Biology, Animal Physiology, Friedrich-Alexander-Universität Erlangen-Nürnberg, 91058 Erlangen, Germany, ${ }^{3}$ Institute of Physiology and Pathophysiology, Friedrich-Alexander-Universität Erlangen-Nürnberg, 91054 Erlangen, Germany, ${ }^{4}$ Institute of Human Genetics, Friedrich-Alexander-Universität Erlangen-Nürnberg, 91054 Erlangen, Germany, ${ }^{5}$ Neurocentre Magendie U1215, INSERM and Université de Bordeaux, Bordeaux 33000, France and ${ }^{6}$ The Research Institute, Nationwide Children's Hospital, Columbus, OH 43205, USA

Address correspondence to D. Chichung Lie, Institute of Biochemistry, Emil Fischer Center, Friedrich-Alexander-Universität Erlangen-Nürnberg, 91054 Erlangen, Germany. Email: chi.lie@fau.de; Julia von Wittgenstein, Department of Biology, Animal Physiology, Friedrich-Alexander-Universität Erlangen-Nürnberg, 91058 Erlangen, Germany. Email: julia.wittgenstein@fau.de

\begin{abstract}
Neuronal activity initiates transcriptional programs that shape long-term changes in plasticity. Although neuron subtypes differ in their plasticity response, most activity-dependent transcription factors (TFs) are broadly expressed across neuron subtypes and brain regions. Thus, how region- and neuronal subtype-specific plasticity are established on the transcriptional level remains poorly understood. We report that in young adult (i.e., 6-8 weeks old) mice, the developmental TF SOX11 is induced in neurons within $6 \mathrm{~h}$ either by electroconvulsive stimulation or by exploration of a novel environment. Strikingly, SOX11 induction was restricted to the dentate gyrus (DG) of the hippocampus. In the novel environment paradigm, SOX11 was observed in a subset of c-FOS expressing neurons (ca. 15\%); whereas around 75\% of SOX11+ DG granule neurons were c-FOS+, indicating that SOX11 was induced in an activity-dependent fashion in a subset of neurons. Environmental enrichment or virus-mediated overexpression of SOX11 enhanced the excitability of DG granule cells and downregulated the expression of different potassium channel subunits, whereas conditional Sox11/4 knock-out mice presented the opposite phenotype. We propose that Sox11 is regulated in an activity-dependent fashion, which is specific to the DG, and speculate that activity-dependent Sox11 expression may participate in the modulation of DG neuron plasticity.
\end{abstract}

Key words: dentate gyrus, hippocampus, immediate early gene, plasticity, Sox11 


\section{Introduction}

Activity-induced plasticity is an essential property of the nervous system. Among other functions, it is a prerequisite for the formation of memory traces and the storage of information. Mechanistically, plasticity is mediated by alterations in synaptic strength and/or intrinsic excitability. Given that anatomical regions and neural networks fulfill distinct functions, it comes as no surprise that the activity-induced plasticity response greatly differs between neuronal subtypes and regions.

An important mechanism to regulate neuronal plasticity and learning is the induction of a group of genes, which are expressed rapidly and transiently upon neuronal activity (Sheng and Greenberg 1990; Minatohara et al. 2015). Many of these so-called immediate early genes (IEGs) encode for TFs, which upon their induction coordinate the expression of plasticityassociated gene expression programs (Flavell and Greenberg 2008). Recent work demonstrated that activity induces distinct transcriptional programs to direct neuronal subtype-specific plasticity (Spiegel et al. 2014; Jaeger et al. 2018). Curiously, known IEG TFs are not expressed in a neuronal subtype-specific manner (Spiegel et al. 2014; Sun and Lin 2016), leaving the question of how neuron subtype-specific plasticity and the associated geneexpression programs are regulated largely unresolved.

To identify transcriptional regulators of region-specific neuronal plasticity, we examined the hippocampus, which is a prominent example of a brain structure in which distinct mechanisms of neuronal plasticity occur within a functional circuit. The hippocampal circuit is classically described as a trisynaptic network, with information flowing from the entorhinal cortex to granule cells in the dentate gyrus (DG), followed by pyramidal neurons of the cornu ammonis (CA) regions 3 and 1 (Knierim 2015). In this circuit, the DG is viewed as critical processing unit because it is the primary recipient of cortical inputs from the entorhinal cortex and has the capacity to convert highly similar inputs into distinct representations, that is, to perform pattern separation (Schmidt et al. 2012; Kesner and Rolls 2015). This capacity is supported by the anatomical organization-DG granule cells vastly outnumber their presynaptic partners in the entorhinal cortex-and a sparse pattern of activity, which results in a divergent flow of information (Schmidt et al. 2012; Lopez-Rojas and Kreutz 2016). In rodents, the DG and the CA1 and CA3 regions-display substantial differences in their activitydependent plasticity response. The DG is set apart from CA1 and CA3 by a higher threshold for the induction of synaptic longterm potentiation (LTP), extremely sparse activity in response to physiological stimuli and the expression of presynaptic LTP at its main output synapse, the mossy fiber terminal (Nicoll and Schmitz 2005; Neunuebel and Knierim 2012; Lopez-Rojas and Kreutz 2016). How hippocampal region-specific properties of plasticity are regulated is not known. The observation that neurons from different hippocampal subfields display profound differences in their activity-associated gene-expression programs (Jaeger et al. 2018), however, strongly suggests that the induction of subtype-specific TFs plays a dominant role in the regulation of hippocampal subfield-specific plasticity.

The HMG-box TF SOX11 is an essential regulator of early neurodevelopmental processes (Kavyanifar et al. 2018), whose expression in the adult brain is almost exclusively observed in regions with ongoing neurogenesis, that is, the subventricular zone/olfactory bulb system and the DG. In these regions, SOX11 expression was observed in neuroblasts and immature neurons, but not in mature neurons (Haslinger et al. 2009; Mu et al. 2012).
Here, we show that SOX11 is induced within hours in mature DG granule cells but not in neurons of the CA subfields of the mouse hippocampus in response to global induction of neuronal activity by electroconvulsive shock (ECS) or a physiological environmental stimulus of hippocampal network activity. Moreover, in vivo SOX11 gain- and loss-of-function revealed that SOX11 modified the intrinsic excitability of DG granule cells. We therefore propose that SOX11 is an activity-dependent TF, which might contribute to the regulation of DG granule cell-specific plasticity.

\section{Materials and Methods}

\section{Animal Experiments}

All animal experiments were carried out in accordance with the European Communities Council Directive (86/609/EEC) and approved by the governments of Upper Bavaria and MiddleFranconia. Female C57Bl/6NRj mice were obtained from Janvier Labs (Le Genest-Saint-Isle, France) and group housed under a $12 \mathrm{~h}$ light/dark cycle with ad libidum access to food and water. In experiments, we used 8-weeks old mice, if not indicated otherwise. Electrophysiological measurements were conducted in slices from 10-weeks old mice. Surgery for stereotactic injections was performed in deeply anesthetized mice using a mixture of Fentanyl $(0.05 \mathrm{mg} / \mathrm{kg})$, Midazolam $(5 \mathrm{mg} / \mathrm{kg})$, and Medetomidine $(0.5 \mathrm{mg} / \mathrm{kg})$. One $\mu \mathrm{L}$ virus solution of Adeno-associated viruses (AAV) Serotype 9 with a titer of $1 \times 10^{11} \mathrm{cfu} / \mathrm{mL}$ encoding either for GFP or for SOX11 was injected into the left and right DG (coordinates from bregma: $\pm 1.6 \mathrm{~mm}$ medial/lateral, $-1.9 \mathrm{~mm}$ anterior/posterior, and $-1.9 \mathrm{~mm}$ ventral/dorsal from brain surface). After surgery anesthesia was antagonized using a mixture of Buprenorphine $(0.1 \mathrm{mg} / \mathrm{kg})$, Atipamezol $(2.5 \mathrm{mg} / \mathrm{kg})$, and Flumazenil $(0.5 \mathrm{mg} / \mathrm{mL})$.

For novel enriched environment (EE) exploration, groups of 4-5 mice were placed from their standard home cage (HC; HC size: $37 \times 21 \times 15 \mathrm{~cm}$ ) into a larger cage (EE cage size: $60 \times 26 \times$ $33 \mathrm{~cm}$ ) containing tubes, climbing grids, plastic caves, and running wheels, and were left to freely explore. The arrangement of objects in the cage was kept constant between different EE experiments. Control mice were brought into the same experimental room but remained in their $\mathrm{HC}$, and were not exposed to exploration of a novel environment.

Application of ECS treatment was performed in mice after anesthesia with sevoflurane gas (Sevorane 100\% v/v, Abbott $\mathrm{GmbH}$ und Co. KG, Wiesbaden, Germany). Electroconvulsive stimuli were given via saline-soaked electrodes attached to both ears of the mice using a constant-current pulse generator. A train of unidirectional square-wave pulses (pulse duration: $2 \mathrm{~ms}, 50 \mathrm{~Hz}$ ) was delivered for $0.5 \mathrm{~s}$. A stimulus of $25 \mathrm{~mA}$ was used in all experiments. Mice displayed a short seizure after ECS followed by a rapid recovery. Mice of the control (sham) treated group were subjected to identical treatment without delivery of the shock.

The Sox11 ${ }^{\mathrm{WT} / \mathrm{WT}}$; Sox $4^{\mathrm{WT} / \mathrm{WT}}$; Tg(YFP; CaMKII:CreER ${ }^{\mathrm{T} 2}$ ) control mouse line (Sox11/4 control) and the Sox $11^{\mathrm{fl} / \mathrm{fl}}$, Sox $4^{\mathrm{fl} / \mathrm{fl}}, \mathrm{Tg}(\mathrm{YFP}$, CaMKII-CreER ${ }^{\mathrm{T} 2}$ ) conditional knockout mouse line (Sox11/4 cKO) were generated by crossbreeding Sox $11^{\mathrm{fl} / \mathrm{fl}}$, Sox $4^{\mathrm{f} / \mathrm{fl}}$ mice (Penzo-Mendez et al. 2007; Potzner et al. 2010) with mice harboring a YFP reporter allele in the ROSA26 locus (Srinivas et al. 2001)

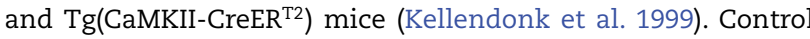
and Sox11/4 cKO line were derived from the same starter breeding pairs. $\mathrm{CreER}^{\mathrm{T} 2}$-mediated recombination in Sox11/4 cKO and 
Sox11/4 control mice was induced at the age of 8 weeks by two intraperitoneal injections of $100 \mu \mathrm{L}$ Tamoxifen $(10 \mathrm{mg} / \mathrm{mL}$ in $10 \%$ ethanol/sunflower seed oil) per day over a 5-day period.

\section{Tissue Processing}

For histological analyses, mice were killed using $\mathrm{CO}_{2}$ and perfused transcardially with phosphate-buffered saline (PBS, $\mathrm{pH}=7.4$ ) followed by $4 \%$ paraformaldehyde (PFA, in phosphate buffer, $\mathrm{pH}=7.4$ ). Brain tissue was postfixed in $4 \%$ PFA overnight and dehydrated in $30 \%$ sucrose solution prior to slicing at a sliding microtome (Leica Microsystems, Wetzlar, Germany).

\section{Immunofluorescence Staining}

Immunofluorescence staining was performed on free-floating sections. Slices were washed four times in Phosphate-buffered saline (PBS; $150 \mathrm{mM} \mathrm{NaCl}, 2.7 \mathrm{mM} \mathrm{KCl}, 8 \mathrm{mM} \mathrm{Na}_{2} \mathrm{HPO}_{4}$,

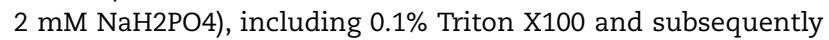
incubated in blocking solution (PBS, 10\% normal donkey serum, $0.25 \%$ Triton X100) for $1 \mathrm{~h}$. Primary antibodies diluted in blocking solution were applied at the following dilutions: goat anti Sox11 (1:250; Santa Cruz, Dallas, TX, USA), rabbit anti Sox11 (1:500; Abcam, Cambridge, UK), mouse anti Calbindin (1:1000, Swant, Marly, Switzerland), rabbit anti Calbindin (1: 1000, Swant), rabbit anti c-FOS (1:500, Santa Cruz), mouse anti c-FOS (1: 500, Santa Cruz), and chicken anti GFP (1:1000, Aves Labs, Tigard, OR, USA). After incubation with primary antibodies for 48$72 \mathrm{~h}$, brain slices were washed six times in PBS and incubated with the following fluorophore-coupled secondary antibodies: Alexa488-coupled anti rabbit IgG, Alexa488-coupled anti goat IgG, Alexa488-coupled anti mouse, FITC-coupled anti chicken IgG, Cy3-coupled anti goat IgG, Cy3-coupled anti rabbit IgG, Alexa647-coupled anti mouse IgG, and Cy5-coupled anti rabbit IgG (1:1000, source: donkey, Jackson ImmunoResearch, West Grove, PA, USA) overnight. The following day, brain slices were subjected to nuclear staining with DAPI ( $2 \mu \mathrm{M}$ in PBS), washed three times and mounted in Aqua Polymount (Polysciences, Warrington, PA, USA) for imaging.

\section{Histology and Counting Procedures}

Confocal single plane and Z-projection images were generated at a Zeiss LSM 780 equipped with four lasers $(405,488,559$, and $633 \mathrm{~nm})$ and $\times 25, \times 40$, and $\times 63$ objectives. Image processing was done in Fiji ImageJ (Schindelin et al. 2012) and included the use of background subtraction via the rolling ball method. Identical parameters for background subtraction were chosen for all images, which were directly compared with each other. In order to quantify cell density, regions of interest (ROI) in Z-projection images were measured in Fiji and cell number within the ROI was counted using the Cell Counter plugin. IF positive cells (as determined by visual inspection of the fluorescence intensity signal) were counted in the respective ROI. For quantification of SOX11 expressing cells upon exposure to EE and for quantification of c-FOS expressing cells in the Sox11/4 cKO mouse lines, from each animal both DGs in a series of 1 out of 12 hippocampal slices were analyzed. In the remaining experiments, the DG in one slice per animal was analyzed. To assess recombination efficiency of the CreER ${ }^{\mathrm{T} 2}$ protein, transduction efficiency of AAVSox11 and SOX11 expression upon ECS, a $0.1 \mathrm{~mm}^{2}$ ROI was randomly selected in the medial part of the dorsal DG. Within this ROI, DG granule cells in one focal plane of a Z-projection image were counted. The ROI comprised a larger part of the medial dorsal DG for analysis of CreER ${ }^{\mathrm{T} 2}$-mediated recombination in neuroblasts and immature neurons, so that 117-157 DCX+ cells were counted per animal. Unless a series of slices was counted, corresponding sections at the level of the dorsal hippocampus were selected for all animals. All slices that were used for quantification of SOX11 expressing cells in the DG were also analyzed for expression of SOX11 in the CA subfields. Slices that were used to analyze c-Fos expression in the motor cortex following EE were used to analyze the expression of SOX11 in the motor cortex. Cell density was calculated as follows: Cell number/(area $\times$ thickness of $\mathrm{Z}$ projection) $\left(\mathrm{mm}^{3}\right)$. Total cell numbers per DG were estimated as follows: Cell number (counted in a one out of 12 series) $\times 12$. For statistical evaluation, the mean cell density for each experimental condition was calculated by averaging cell density per animal over all animals of a treatment group. Experimenters were blinded to experimental conditions.

\section{Generation of AAV}

AAV9 was produced according to previously described protocols (Foust et al. 2009). In brief, Sox11 cDNA was cloned into AgeI and HindII sites of the double stranded AAV2 vector, which allows transgene expression under the CMV early enhancer/chicken beta actin (CAG) promoter. AAV9 was produced by transient transfection with a plasmid encoding Rep2Cap9 sequence along with an adenoviral helper plasmid (pHelper, Stratagene, La Jolla, CA) in 293 human embryonic kidney cells. Virus was purified by a Cesium chloride density gradient and purity was verified by $4-12 \%$ SDS-Acrylamide gel electrophoresis and silver staining (Invitrogen, Carlsbad, CA). Vector preparations were titered by quantitative-PCR using Taq-Man technology. Viruses were stored at $4{ }^{\circ} \mathrm{C}$ until use. For stereotactical injections, viruses were diluted to a titer of $1 \times 10^{11} \mathrm{cfu} / \mathrm{mL}$.

\section{RNA Isolation and cDNA Preparation}

For mRNA expression analyses, the DG was microdissected from unfixed brain tissue. Mice were killed by cervical dislocation and the DG was dissected as described (Hagihara et al. 2009). The prepared tissue was stored in stabilizing RNAlater buffer (Qiagen, Cat No./ID: 76154) at $-80{ }^{\circ} \mathrm{C}$ until RNA was isolated using the RNeasy Kit (Qiagen, Cat No./ID: 74106) according to the manufacturer's instructions. About 300 ng of RNA were used for cDNA synthesis with the SuperScript III First-Strand Synthesis System (ThermoFischer Scientific, Waltham, MA, USA). We utilized OligodT-Primer to specifically amplify poly-adenylated mRNA.

\section{Real-Time Quantitative PCR (qPCR) Analysis}

Real-time qPCR was performed on a StepOne device (96-well format, Applied Biosystems, Forster City, CA, USA) or on a Roche Light Cycler (384-well format) using Power SYBR Green PCR Master Mix (ThermoFischer Scientific, Waltham, MA, USA) according to the manufacturer's instructions. For each experimental group cDNA from 4 to 5 independent biological replicates was used. Changes in mRNA expression were quantified by using the delta $\mathrm{C}_{\mathrm{T}}$ method. Mean $\mathrm{C}_{\mathrm{T}}$ values of each target gene were normalized to the mean $\mathrm{C}_{\mathrm{T}}$ values of two housekeeping genes (Hprt and RPL27) and fold changes were calculated by normalizing each $\Delta \Delta \mathrm{C}_{\mathrm{T}}$ value to the mean $\Delta \Delta \mathrm{C}_{\mathrm{T}}$ value of all control samples. The following primer pairs were used for qPCR analysis: $5^{\prime}$-CCC 
TGT CGC TGGTGG ATA AG-3' (Sox11, fwd); 5'-GGT CGG AGA AGT TCG CCT C-3' (Sox11, rev); 5'-CCTGGATAAACTGTGGACATTGG3' (RPL27, fwd); 5'-TGTAGTAGCCTGATCGAACAACA-3' (RPL27, rev); 5'-TGGAAAGAATGTCTTGATTGTTG-3' (Hprt, fwd); 5' CGAGAGGTCCTTTTCACCAG-3' (Hprt, rev); 5'-TGGCCATTTTAGGGAAAGGTGA-3' (Kcnh5, fwd); 5'-TTGAGCAAGGCTTCTCGCTT-3' (Kcnh5, rev); 5'-GTGATTACACGTGCGCTTCTG-3' (Kcnc2, fwd); 5'-ACTGAACAGTTAGAGGGTGGG-3' (Kcnc2, rev);

\section{RNA Sequencing}

RNA extraction was performed using RNeasy Kit (Qiagen, Cat No./ID: 74106) according to the manufacturer's protocol. Before and during the library preparation the quality of RNA was analyzed using a 2100 Bioanalyzer system (Agilent Technologies). Barcoded RNA sequencing libraries were prepared from $100 \mathrm{ng}$ total RNA using TruSeq Stranded mRNA Sample Preparation Kit, according to the manufacturer's instructions (Illumina, San Diego, CA, USA). Sequencing (single-end; $101 \mathrm{bp}$ ) was performed on a HighSeq-2500 platform (Illumina). After quality filtering with cutadapt v. 1.9.1 (Martin 2011); reads were mapped against the mouse reference genome (Ensembl GRCm38, release 85) using the STAR aligner v. 2.5.2a (Dobin et al. 2013), and a STAR genome directory created by supplying the Ensembl gtf annotation file (release 85) for GRCm38. Read counts per gene were obtained using featureCounts program v. 1.5.1 (Liao et al. 2014) and the Ensembl gtf annotation file. Following analyses were performed using R version 3.3.1 ( $\mathrm{R}$ Core Team 2015). In particular, differential expression analysis was performed with the DESeq2 package v.1.12.3 (Love et al. 2014). Genes with BenjaminiHochberg adjusted $P$-value less than 0.05 were considered differentially expressed. Gene ontology-based enrichment analysis for differentially expressed genes that were at least 1.5-fold up- or down-regulated was performed with FunRich software (Pathan et al. 2015). RNA-sequencing data were deposited in the NCBI gene expression and hybridization array data repository (GEO) database and have the accession number GSE140180.

\section{Slice Electrophysiology}

As described previously (Zheng et al. 2012), transverse hippocampal slices of $350 \mu \mathrm{m}$ thickness were prepared in ice-cold sucrose-based artificial cerebrospinal fluid (aCSF) from control mice, Sox11/4 cKO mice and SOX11-overexpressing mice (46 weeks after virus injection), anesthetized with sevoflurane. Slices were first incubated in sucrose-aCSF at $35^{\circ} \mathrm{C}$ for $10 \mathrm{~min}$ and then in modified aCSF containing (in $\mathrm{mM}$ ) $125 \mathrm{NaCl}, 3 \mathrm{KCl}$, $1 \mathrm{CaCl}_{2}, 3 \mathrm{MgCl}_{2}, 1.25 \mathrm{NaH}_{2} \mathrm{PO}_{4}, 25 \mathrm{NaHCO}_{3}$, and $10 \mathrm{D}$-glucose at room temperature for at least $2 \mathrm{~h}$ before being used. Individual slices were transferred to a submerged chamber perfused with normal aCSF with $1.3 \mathrm{mM} \mathrm{MgCl} 2$ and $2.5 \mathrm{mM} \mathrm{CaCl}_{2}$ at near physiological temperature $\left(30-32{ }^{\circ} \mathrm{C}\right)$. All solutions were constantly gassed with $95 \% \mathrm{O}_{2}-5 \% \mathrm{CO}_{2}$. Electrophysiological signals were filtered at $6 \mathrm{kHz}$ and collected at $20 \mathrm{kHz}$ with the use of a Multiclamp 700B amplifier in conjunction with Digidata 1440A interface and pClamp10 software (Molecular Devices, CA).

Whole-cell recordings from randomly chosen cells located in the outer one-third granule cell layer (GCL) from the suprapyramidal blade were performed with patch-pipettes filled with (in $\mathrm{mM}) 135 \mathrm{~K}$-gluconate, $5 \mathrm{HEPES}, 3 \mathrm{MgCl}_{2}$, 5 EGTA, $2 \mathrm{Na}_{2} \mathrm{ATP}, 0.3$ $\mathrm{Na}_{3} \mathrm{GTP}$, and $4 \mathrm{NaCl}$ ( $\mathrm{pH}$ 7.3). The passive membrane properties of the cells (e.g., capacitance, input resistance) were collected from membrane test right after breaking into whole-cell mode with voltage clamped at $-70 \mathrm{mV}$. Action potentials (APs) of the granule cells were recorded in current-clamp mode. DG granule cells have very negative resting membrane potential (RMP) and normally do not discharge spontaneously. To test cell excitability, a depolarizing protocol with a ramp test (ranging from 0 to $100 \mathrm{pA}$ within $2 \mathrm{~s}$ ) was used to elicit APs from either RMP or $-70 \mathrm{mV}$ (held by current injection). The number of APs during ramps was measured and compared between groups. The first AP appearing during a ramp depolarization was used to determine current strength for AP induction.

Hippocampal slices were subjected to immunofluorescence staining against SOX11 and GFP after the electrophysiological recordings to confirm transgene expression in the DG. Slices without transgene expression were omitted from data analysis.

\section{Statistics}

One-way-ANOVA followed by a Dunnet's Multiple Comparison test was applied to assess statistical significance of the differences between single time points versus control treatment in $\mathrm{EE}$ experiments. To calculate statistical significance for qPCR analyses of potential SOX11 target genes, for electrophysiological data, for SOX11 expression upon ECS and for c-FOS expression in Sox11/4 control versus cKO mice, unpaired Student's t-test was used. A Mann-Whitney-U test was applied to compare SOX11 expression between Sox11/4 control and cKO mice.

\section{Results}

\section{Sox11 is Induced by Hippocampal Activity in a Region-Specific Manner}

To identify candidates for activity-dependent DG-specific TFs, we analyzed a recently published resource describing DGspecific chromatin signatures and the dynamic transcriptomic changes in the DG following ECS treatment (Su et al. 2017). We speculated that DG neuron-specific expression of activity induced TFs may in part be regulated by distinct chromatin accessibility patterns. DG-specific open chromatin signatures were found in the proximity of 6602 genes, 331 of which encode for TFs. Of these factors, 129, 117, and 74 were differentially expressed 1, 4, and $24 \mathrm{~h}$ after ECS, respectively (Supplementary Fig. S1A). At $1 \mathrm{~h}$ after ECS, the top 15 upregulated TFs comprised IEGs with known activity-dependent expression and function across hippocampal subfields such as Egr1, the AP-1 members JunD and Fosl2 and the NGFI-B nuclear receptor subfamily four members Nr4a1, Nr4a2, and Nr4a3 (Cheval et al. 2012; McNulty et al. 2012; Chen et al. 2014). Consistent with the rapid and transient activation of IEGs, expression of these TFs decreased toward later time points with Fosl2 being the only IEG that was still among the 15 highest upregulated TFs at $4 \mathrm{~h}$ after ECS. The only other TF that was among the top 15 at both the 1 and $4 \mathrm{~h}$ time point was the neurodevelopmental regulator Sox11 (Supplementary Fig. S1A). The latter observation is in line with a previous microarray-based analysis reporting increased Sox11 mRNA expression in the adult rat hippocampus few hours after ECS (Sun et al. 2005). Compared with the other TFs with strong induction after ECS, Sox11 was the only top $15 \mathrm{TF}$, whose expression increased towards the $4 \mathrm{~h}$ time point and, in addition, displayed the most DG-restricted expression pattern under baseline conditions (Supplementary Fig. S1B and C). Thus, we focused our investigations upon Sox11 as a candidate for a DGspecific activity-dependent gene. 
Increased Sox11 expression following ECS has only been demonstrated on mRNA level (Sun et al. 2005; Su et al. 2017). We observed a clearly increased fraction of SOX11 immunoreactive cells in the DG $6 \mathrm{~h}$ after ECS [\% SOX11+ cells over DAPI: control $=2.4 \pm 0.6 \%$; ECS $=83 \pm 7.1 \%$; $P$-value (Control vs. ECS) < 0.0001] (Supplementary Fig. S2), demonstrating that ECS also induced the expression of SOX11 protein. Under control conditions, SOX11 immunoreactivity was restricted to the subgranular zone (SGZ) of the DG, that is, the region harboring neuroblasts and immature adult-generated neurons. Following ECS, we surprisingly detected SOX11 immunoreactivity throughout the GCL, that is, the region that is mainly populated by mature DG neurons, raising the possibility that ECS-induced SOX11 expression in mature granule cells (Supplementary Fig. S2B).

ECS treatment generates massive synchronized neuronal activity and results in large scale epigenetic and transcriptomic changes in the DG (Ma et al. 2009), which may not reflect changes in chromatin structure and gene expression induced by physiological neuronal activity. A variety of pathological stimuli including stroke, neurotoxin challenge, and axotomy induces Sox11 expression in neurons, which has led to the hypothesis that Sox11 expression is part of a general neuronal injury response (Kavyanifar et al. 2018). To investigate, whether it is possible to induce Sox11 expression by physiological hippocampal activity, C57Bl/6 mice were placed into a novel, EE (Deng et al. 2013) and analyzed at different time points after the exposure (Fig. 1A). HC housed mice served as controls. Sox11 mRNA levels were transiently elevated by exposure to an EE condition with peak expression levels at the $3 \mathrm{~h}$ EE time point [P-value (HC vs. $3 \mathrm{~h} \mathrm{EE}$ ) $=0.005]$. After $6 \mathrm{~h}$ EE exploration and $2 \mathrm{~h}$ after $6 \mathrm{~h}$ EE exploration, Sox11 mRNA levels returned to control levels (Fig. 1B). To determine whether EE increased SOX11 protein expression and to analyze the distribution of SOX11 expressing cells, we performed immunofluorescence staining of SOX11. Consistent with the expression of SOX11 by neuroblasts and immature adult-generated DG neurons (Haslinger et al. 2009; Mu et al. 2012), we observed numerous SOX11+ cells in the SGZ of the DG in all experimental groups (Fig. 1C). Under all conditions, we also observed occasional SOX11+ cells in the hilus (Fig. 1C). The identity of these hilar SOX11+ remains to be determined: Hilar SOX11+ cells were negative for the astrocyte and stem cell marker SOX2, and some showed a faint immunoreactivity for the neuronal marker NeuN (data not shown); given the small size of the soma it appears, however, unlikely that SOX11+ hilar cells were mossy cells.

In HC housed animals, SOX11+ cells were only rarely found in the GCL (density of SOX11+ cells in the GCL: $6450 \pm 1565$ cells $/ \mathrm{mm}^{3}$; total SOX11+ cell number: $912 \pm 226$ cells/DG; Fig. 1D). In contrast, SOX11 expressing cells were frequently observed in the GCL of mice that had been exposed to EE exploration. Costaining with the Calcium-binding protein Calbindin (Sloviter 1989) confirmed that SOX11+ cells in the GCL were mature DG neurons (Fig. 1E).

In the following, we focused on the analysis of SOX11+ cells in the GCL. The number of SOX11+ cells in the GCL peaked after 6 h of EE exploration [SOX11+ cell density $=34436 \pm 14325$ cells $/ \mathrm{mm}^{3}$; P-value (HC vs. $\left.6 \mathrm{~h} \mathrm{EE}\right)=0.001$; total SOX11+ cell number: $8184 \pm 1800$ cells/DG]. Two hours after $6 \mathrm{~h}$ EE [SOX11+ cell density $=19401 \pm 10313$ cells $/ \mathrm{mm}^{3}$; P-value (HC vs. $6 \mathrm{~h}$ $\mathrm{EE}+2 \mathrm{~h} \mathrm{HC}$ ) $=0.126$; total SOX11+ cell number: $3420 \pm 1314$ cells/DG] and $18 \mathrm{~h}$ after $6 \mathrm{~h}$ EE densities of SOX11+ cells were indistinguishable from controls, that is, HC housed animals
[SOX11+ cell density $=3917 \pm 1453$ cells $/ \mathrm{mm}^{3}, P$-value (HC vs. $6 \mathrm{~h} \mathrm{EE}+18 \mathrm{~h} \mathrm{HC})=0.977$, total sOX11+ cell number: $540 \pm 131$ cells/DG] (Fig. 1D). Collectively, these data demonstrate that SOX11 is transiently induced in mature DG neurons by a physiological hippocampal stimulus.

In contrast to ECS conditions, the SOX11 expression pattern following EE stimulation was confined to a subpopulation of DG neurons and was highly reminiscent of the DG characteristic sparse neuronal activation pattern (Soule et al. 2008). To investigate if SOX11 is induced in activated DG neurons, we compared the expression of SOX11 and of the activity-dependent IEG cFOS at the time of SOX11 peak expression (6 h EE). Around 15\% $(15 \pm 6.1 \%$, equivalent to $46 \pm 23$ out of $305 \pm 114$ cells/DG in one hippocampal slice; SOX11+, c-FOS + cell density $=11603 \pm 5723$ cells $/ \mathrm{mm}^{3}$; c-FOS + cell density $=77044 \pm 16021$ cells $/ \mathrm{mm}^{3}$ ) of cFOS+ DG neurons coexpressed SOX11 (Fig. 2). More strikingly, we found almost $80 \%$ ( $76 \pm 14.9 \%$, equivalent to $46 \pm 23$ out of $57 \pm 35$ cells/DG in one hippocampal slice; SOX11+ cell density $=15291 \pm 6553$ cells $/ \mathrm{mm}^{3}$ ) of SOX11+/Calbindin + cells to be C-FOS+, demonstrating that the vast majority of SOX11+ mature granule cells belonged to a neuronal population, which had responded to stimulation. These results strongly indicate that the TF SOX11 is expressed in individual mature DG neurons in an activity-dependent fashion.

Exploration of a novel environment and the memory representation formed afterward involve activity of all hippocampal subfields and distinct cortical areas (Kesner and Rolls 2015). Accordingly, high numbers of c-FOS+ activated neurons were observed following $6 \mathrm{~h}$ of EE in all hippocampal subfields and the motor cortex (Fig. 3A). In contrast, SOX11+ cells were never observed in the CA subfields and the motor cortex and were confined to the DG (Fig. 3A). ECS causes supraphysiological synchronized neuronal activity in the DG and the CA subfields (Guzowski et al. 1999; French et al. 2001). Despite the widespread activation of hippocampal neurons by ECS, SOX11 expression was only induced in DG neurons $6 \mathrm{~h}$ after ECS treatment (Fig. 3B). CA regions were extensively analyzed for SOX11 expressing cells. However, we never detected any SOX11+ cells in the CA regions under HC conditions or following ECS. Collectively, these results indicate that within the hippocampal circuit neuronal activitydependent regulation of SOX11 is a distinct property of DG neurons.

\section{SoX11 Has the Ability to Modify DG Granule Cell Excitability}

To date, SOX11 has almost exclusively been linked to early neurodevelopmental processes such as neural progenitor survival, fate determination, and neuronal migration (Kavyanifar et al. 2018). We next asked whether SOX11 has the potential to alter mature DG granule cell properties. To this end, we overexpressed SOX11 in DG cells of young adult C57Bl/6 mice via stereotactic injection of an Adeno-associated virus serotype 9 (AAV) coding for SOX11. Mice injected with an AAV coding for GFP served as controls. Efficient AAV-encoded transgene expression occurs with a delay of 2-4 weeks (Klein et al. 2008). Accordingly, we observed widespread transgene expression in the DG GCL 4 weeks after virus injection ( $>90 \%$ of neurons being SOX11 positive with $40 \pm 4.9 \%$ of neurons being strongly SOX11 positive; $n=3$ ) and chose this time point for subsequent analyses (Fig. 4A). Next to dentate granule cells, we observed transgene expression in some hilar neurons and neurons in the CA3 subfield, indicating lateral and ventral spreading of 


\section{A Experimental Paradigm Enriched} Environment (EE):

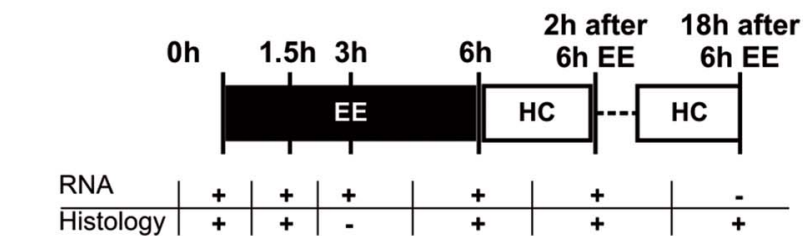

C
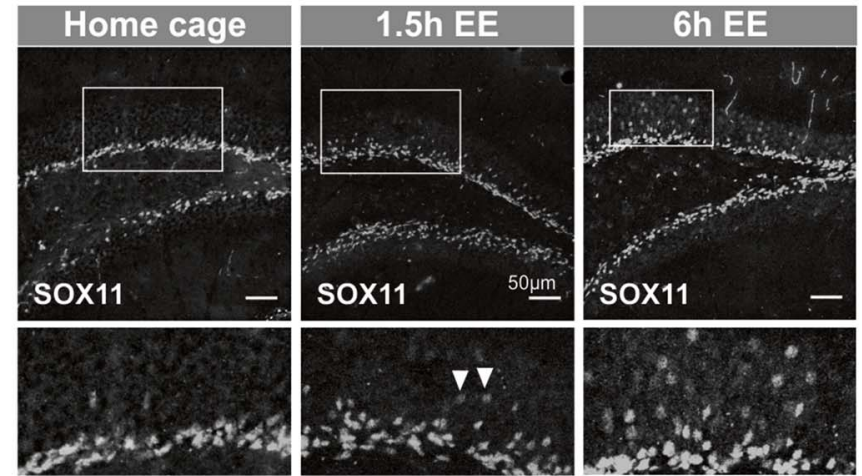

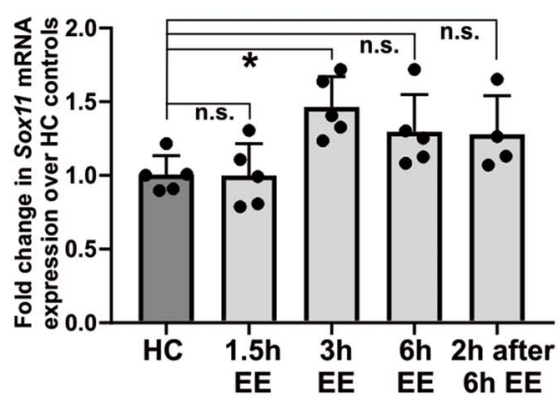

D Sox11 expressing GCs outside SGZ: $E$
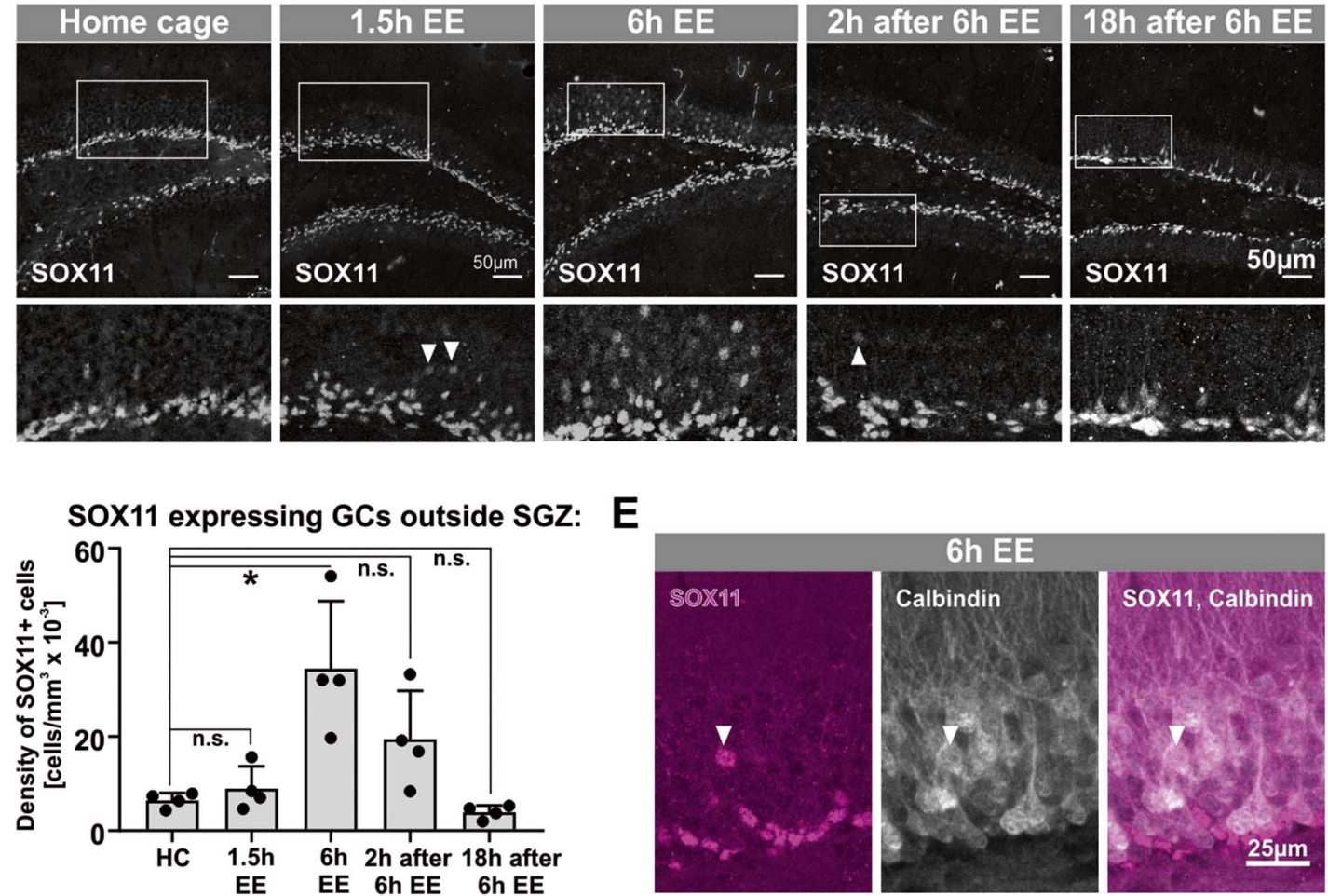

Figure 1. Sox11 expression is induced in mature DG granule cell neurons (GCs) upon exploration of a novel EE. (A) Schematic representation of the paradigm used for EE experiments. C57Bl/6 mice were sacrificed at various time points to extract RNA from DG tissue or to fix brain tissue for IF staining. (B) Effect of EE exploration on Sox11-mRNA levels. Sox11 mRNA expression displayed a transient increase upon EE exploration, which peaked after $3 \mathrm{~h} E E(F C=1.5 \pm 0.25 ; P=0.005)(n=4-5)$. $(C)$ Immunostaining of SOX11 at various time points after EE. Upon EE exploration single SOX11-positive cells were observed deep within the GCL, suggesting a mature phenotype. In contrast, SOX11 expression in control mice was limited to the SGZ. (D) Quantification of SOX11-expression by cells outside the SGZ upon exploration of an $\mathrm{EE}$ in comparison with HC conditions. Activity-induced SOX11 expression peaked after $6 \mathrm{~h}$ EE (density $(\mathrm{HC})=6450 \pm 1565 \mathrm{cells} / \mathrm{mm}^{3} \mathrm{vs}$. density $(6 \mathrm{~h} \mathrm{EE})=34436 \pm 14325$ cells $/ \mathrm{mm}^{3} ; \mathrm{P}=0.001$ ). All results are displayed as mean $\pm \mathrm{SD}$. (E) Costaining of SOX11 with the mature GC marker Calbindin. Colocalization of SOX11 (magenta) and Calbindin (gray) confirmed that SOX11+ cells located within the GCL were mature GC neurons.

the virus from the injection site (Supplementary Fig. S3A and B). Consistent with the tropism of AAV9 for mature neurons (Cearley et al. 2008), we found transgene expression in only a small fraction of SOX2-expressing astrocytes $(21 \pm 3.1 \%)$ and of DCX-expressing immature neurons $(6.1 \pm 1.7 \%)$ in the DG.

Because AAV9-mediated overexpression did not exclusively target DG neurons, we focused in the following on the analysis of intrinsic properties of DG granule cells rather than on the analysis of network effects. To examine whether SOX11 modified electrophysiological properties of DG granule cells, we performed whole-cell recordings in acute hippocampal slices from GFP- or SOX11-OE mice starting from 4 weeks after AAV injection. Mice were 6 weeks old at the time point of virus injection. To avoid recordings from adult-generated immature DG granule cells, we selected cells based on their localization distant from the SGZ and their input resistance $(<450 \mathrm{M} \Omega)$, which is substantially lower in mature than in immature granule cells (Schmidt-Hieber et al. 2004). Compared with AAV-GFPgranule cells $(n=18)$, their AAV-Sox11-counterparts $(n=22)$ displayed a significantly enhanced input resistance (Rm; AAVGFP: $305 \pm 13 \mathrm{M} \Omega$; AAV-Sox11: $346 \pm 13 \mathrm{M} \Omega ; \mathrm{P}=0.033)$, whereas RMP remained unchanged (AAV-GFP: $-83.6 \pm 1.0 \mathrm{mV}$; AAV-Sox11: $-84.8 \pm 0.7 \mathrm{mV} ; \mathrm{P}=0.76$ ). When we interrogated the discharge behavior of granule cells during ramp-like depolarizing current injections starting either from RMP or from $-70 \mathrm{mV}$, SOX11-OE neurons proved to be much more responsive and exhibited a 
A

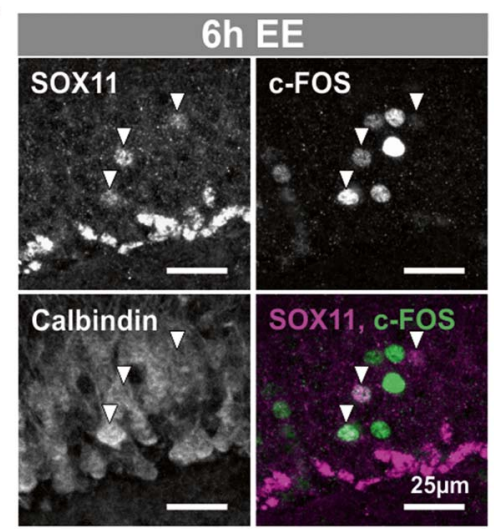

B
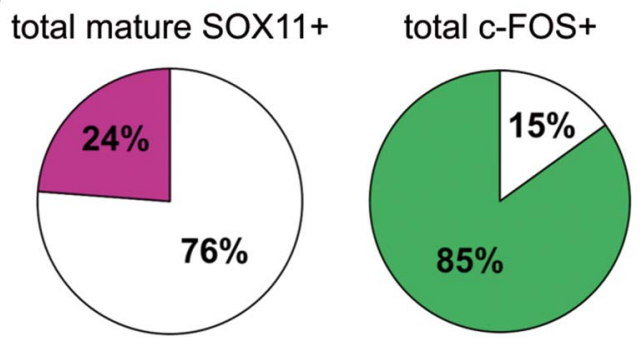

only SOX11+

only c-FOS+

SOX11+, C-FOS+

Figure 2. The majority of SOX11+ mature GCs coexpress the IEG c-FOS. (A) Immunostaining of SOX11 (magenta), c-FOS (green) and Calbindin (gray) in $\mathrm{C} 57 \mathrm{Bl} / 6$ mice after $6 \mathrm{~h}$ EE exploration reveals the co-expression of SOX11 and c-FOS. (B) Counting of SOX11, c-FOS double-positive cells in the DG after $6 \mathrm{~h} \mathrm{EE}$ exploration confirmed that the vast majority of mature SOX $11+(76 \pm 14.9 \%)$ cells belong to an activated, c-FOS expressing neuronal subpopulation. SOX11+ cells constitute a fraction of $15 \pm 6.1 \%$ among all c-FOS expressing mature GCs. Values are expressed as mean $\pm S D$ of results from five different animals per group.

significantly higher firing propensity compared with control neurons (Fig. $4 B$ and $C$ ). The increased discharges during ramp test in SOX11-OE neurons were accompanied by significant reduction in rheobase (the minimal current to induce the first AP; from $-70 \mathrm{mV}$ : control AAV-GFP $55.6 \pm 2.8$ pA; SOX11-OE $38.0 \pm 1.7$ pA, $P=0.008$; Fig. $4 B)$, but not in AP threshold $(-45.4 \pm 0.7 \mathrm{mV}$ vs. $-45.1 \pm 0.5 \mathrm{mV} ; \quad P=0.74)$. These findings show that overexpression of SOX11 in mature granule cells engenders a considerable rise in their intrinsic excitability.

To examine whether similar changes in granule cell excitability occur in a setting, which induces SOX11 expression under physiological conditions, we measured intrinsic properties of DG granule cells in C57Bl/ 6 wildtype mice after exposure to EE. For this purpose, mice were either transferred to a novel EE cage over night or remained in their HC. When tested afterward, DG granule cells from mice exposed to EE exhibited a similar combination of elevated input resistance (no EE: $n=47,302.6 \pm 6.5 \mathrm{M} \Omega$; $+\mathrm{EE}: n=19,335.5 \pm 12.7 \mathrm{M} \Omega ; P=0.016$ ), unchanged RMP (no EE: $-86.0 \pm 0.6 \mathrm{mV} ;+\mathrm{EE}-86.4 \pm 0.6 \mathrm{mV}$ ) and enhanced excitability as they fired significantly more APs upon ramp-like depolarizations in comparison with granule cells from nonenriched, that is, HC-housed control animals (Fig. 4D; from $-70 \mathrm{mV}$ : AP number: no EE: $16.3 \pm 1.2$; $+E E: 21.3 \pm 1.8, P=0.009)$. Consistent with our findings from SOX11-OE neurons, EE reduced rheobase, but did not alter AP threshold (rheobase: no EE: $49.4 \pm 1.9 \mathrm{pA}$;
$+\mathrm{EE}: 38.9 \pm 2.2 \mathrm{pA}, \mathrm{P}=0.003$; AP threshold: no $\mathrm{EE}-46.6 \pm 0.5 \mathrm{mV}$, $+\mathrm{EE}-47.6 \pm 1.4 \mathrm{mV}, \mathrm{P}=0.35)$.

\section{Loss of Sox11 and Sox4 Reduces Intrinsic Excitability of Mature DG Granule Cells}

To further test the potential of SOX11 to modulate granule cell excitability, we investigated whether a loss of SOX11 from mature DG granule cells would influence granule cell spiking behavior. During murine development, the closely related TF SOX4 functions redundantly to SOX11 and is able to compensate the loss of SOX11: thus, SOX4 and SOX11 single mutant mice show an overall normal central nervous system development, whereas major CNS defects occur when both SOX factors are deleted (Cheung et al. 2000; Bhattaram et al. 2010). Because of this potential to function redundantly and to prevent compensation of SOX11 deletion by upregulation of SOX4, we decided to concomitantly ablate Sox4, although we did not observe SOX4 expression in mature DG neurons under basal (HC) and stimulated (i.e., EE or ECS) conditions (J Wittgenstein and DC Lie, unpublished observation). For ablation of Sox11 and Sox4 from DG granule neurons, we generated the Sox $11^{\mathrm{fl} / \mathrm{fl}}$, Sox4 $4^{\mathrm{fl} / \mathrm{fl}}, \mathrm{Tg}\left(\mathrm{YFP}, \mathrm{CaMKII-CreER^{ \textrm {T } 2 }}\right.$ ) mouse line (hereafter Sox11/4 CKO; Fig. 4E); the Sox11 WT/WT; Sox4 ${ }^{\text {WT/WT }}$; Tg(YFP; CaMKII:CreERT2) mouse line (hereafter Sox11/4 control; Fig. 4E) served as control. YFP-reporter expression confirmed widespread Tamoxifeninduced recombination by CaMKII-CreER ${ }^{\mathrm{T} 2}$ in principal forebrain neurons including DG granule cells ( $83 \pm 7.8 \%$ of neurons being YFP positive; $n=4$; Supplementary Fig. S4A) (Erdmann et al. 2007). Further phenotyping of YFP-reporter positive cells in the DG demonstrated that recombination was largely restricted to mature DG neurons with only $6 \%$ of all DCX+ neuroblasts and immature neurons being positive for YFP (Supplementary Fig. S4A). To validate the deletion of Sox11 from mature DG granule cells, mice were exposed to conditions that induced Sox11 expression in mature DG granule cells (i.e., $6 \mathrm{~h} \mathrm{EE)} \mathrm{and}$ were subsequently analyzed for SOX11 immunoreactivity. Consistent with the successful deletion of Sox11 from mature DG granule cells, almost no SOX11 immunoreactivity was detectable in mature DG neurons of Sox $11 / 4$ cKO mice after exposure to $6 \mathrm{~h} \mathrm{EE}$, whereas the DG of Sox $11 / 4$ control mice exposed to $6 \mathrm{~h}$ EE harbored numerous SOX11+ mature granule cells (density of SOX11+ cells in the GCL of controls: $23748 \pm 18159$ cells $/ \mathrm{mm}^{3}$ vs. cKOs: $2870 \pm 1078$ cells $/ \mathrm{mm}^{3} ; P$-value $=0.048$; Supplementary Fig. S4B and C).

We then performed whole-cell recordings in hippocampal slices from Sox11/4 cKO mice and Sox11/4 control mice starting from 4 weeks after tamoxifen treatment. As before, discharge behavior of DG granule cells was measured during ramplike depolarizations from RMP or $-70 \mathrm{mV}$. Unexpectedly, granule cells of HC-housed Sox11/4 control mice showed elevated excitability compared with granule cells of HC-housed wildtype and AAV-GFP injected C57Bl/6 mice (compare Fig. $4 \mathrm{~F}$ with Fig. $4 C$ and $D$ ), most likely reflecting a peculiarity associated with their transgene background. Irrespective of the higher level of excitability in this control group, the electrophysiological phenotype of granule cells from Sox11/4 cKO mice displayed almost the exact opposite to that of granule cells from SOX11$\mathrm{OE}$ or EE-exposed mice. When determined by ramps starting from $-70 \mathrm{mV}$, the firing behavior was substantially dampened (Fig. 4F). Concomitantly, rheobase increased (Sox11/4 controls, $n=20,37.5 \pm 1.9 \mathrm{pA}$; Sox $11 / 4 \mathrm{cKO}, n=21,49.1 \pm 3.0 \mathrm{pA} ; \mathrm{P}=0.006$ ) and input resistance decreased (Sox11/4 controls $318.9 \pm 8.9 \mathrm{M} \Omega$; 
A
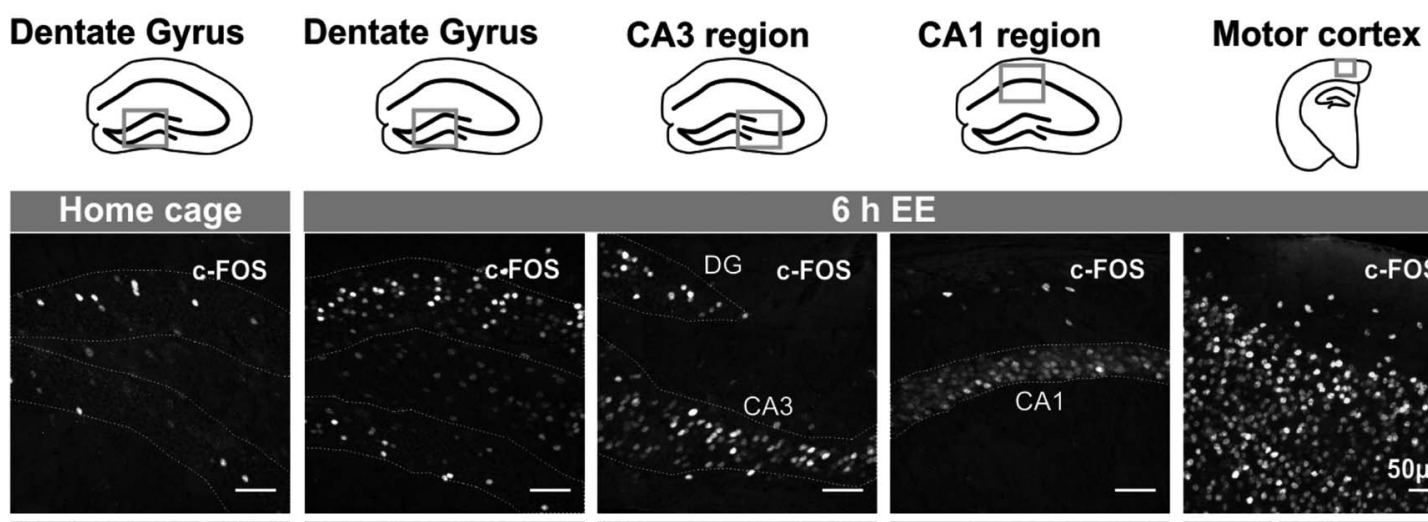

\section{6 h EE}
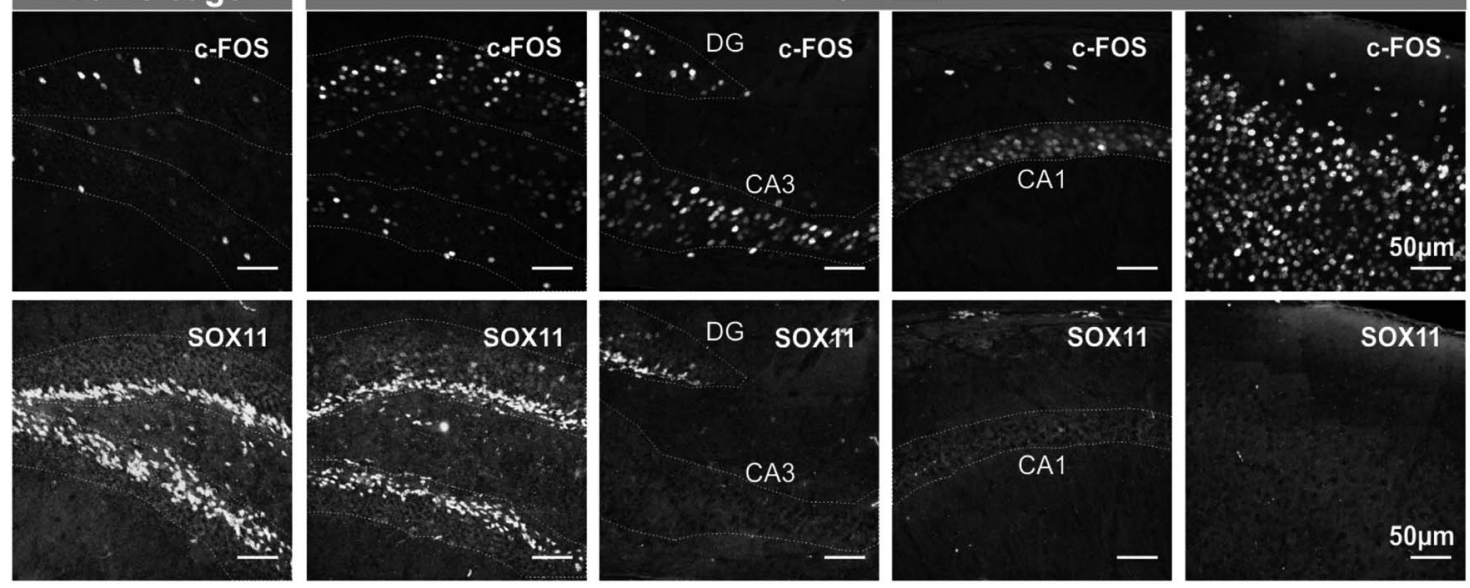

B
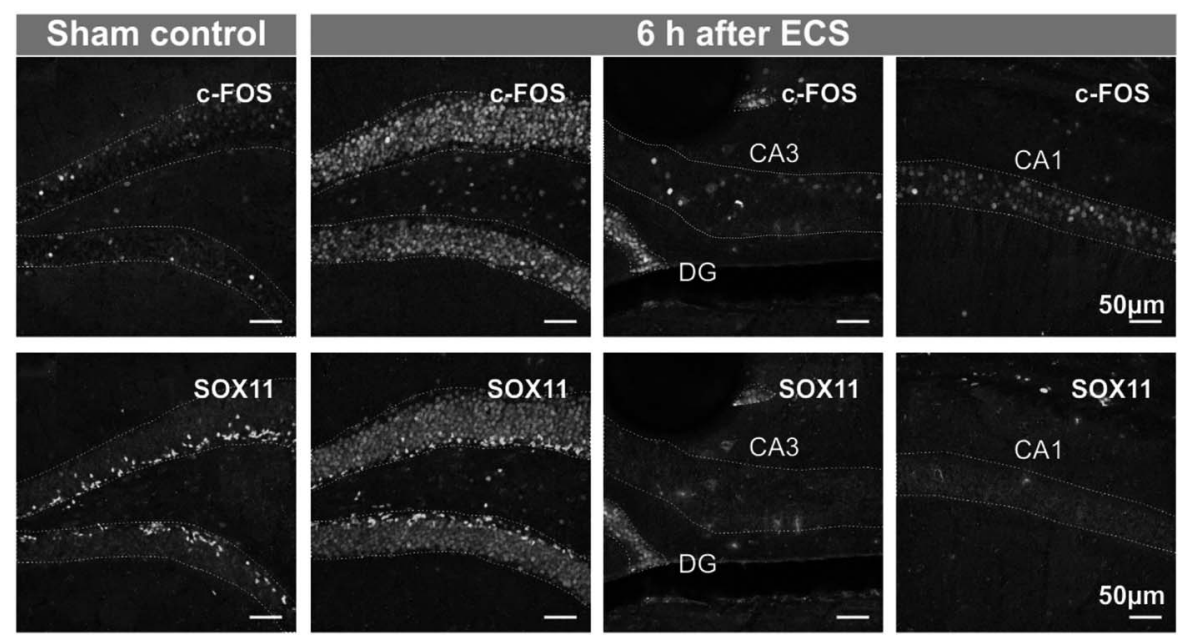

Figure 3. Activity-dependent expression of SOX11 is specific for the DG. (A) Immunostaining of SOX11 and c-FOS in different brain regions after $6 \mathrm{~h}$ EE exploration. The three hippocampal subregions and the motor cortex were examined for expression of c-FOS and SOX11. Schematic drawings in the upper panel represent the region of interest. Although c-FOS expression was high in all regions, SOX11 could only be detected in the DG. (B) Immunostaining of SOX11 and c-FOS in the hippocampal regions $6 \mathrm{~h}$ after ECS showed that SOX11 was only induced in the DG and not in the CA3 or CA1 region, while c-FOS+ cells were detected in CA3 and CA1 region.

Sox11/4 cKO 285.4 $\pm 8.2 \mathrm{M} \Omega ; \mathrm{P}=0.008$ ), whereas RMP (Sox11/4 controls $-85.9 \pm 0.7 \mathrm{mV}$; Sox11/4 cKO $-85.9 \pm 0.9 \mathrm{mV}$ ) and $\mathrm{AP}$ threshold remained unaltered (Sox11/4 controls $-46.6 \pm 0.5 \mathrm{mV}$; Sox $11 / 4 \mathrm{cKO}-45.6 \pm 0.9 \mathrm{mV}, \mathrm{P}=0.37)$. In line with this alteration in electrophysiological properties, Sox11/4 cKO mice displayed a reduced probability to express c-FOS upon physiological hippocampal activity. Following EE exploration for $30 \mathrm{~min}$, Sox11/4 cKO mice showed in comparison with Sox11/4 control mice a significantly lower density of c-FOS + cells in the DG (density of c-FOS + cells in control mice: 38470 cells $/ \mathrm{mm}^{3} \pm 3833$; total cell number: $6215 \pm 1089$ cells/DG vs. density of c-FOS+ cells in cKO mice: 31355 cells $/ \mathrm{mm}^{3} \pm 3105$; total cell number: $4779 \pm 1049$ cells/DG; $P=0.028$; Supplementary Fig. S5). Collectively, these data lend further support to the concept that the expression of
SOX11 serves as a molecular switch to tune the firing properties of DG granule cells in an activity-dependent fashion.

\section{SOX11 Regulates Potassium Channel Subunit Expression in DG Neurons}

To investigate transcriptional programs downstream of SOX11 in mature DG granule cells, we performed a transcriptome analysis of SOX11-OE DG tissue. We microdissected the DG of AAV-GFP- and AAV-Sox11-injected mice 4 weeks after virus injection and analyzed the tissue by RNA sequencing (Fig. 5A). About 267 genes and 104 genes were significantly upregulated and downregulated, respectively, by more than 1.5-fold after overexpression of SOX11 (Supplementary Table S1). Gene 


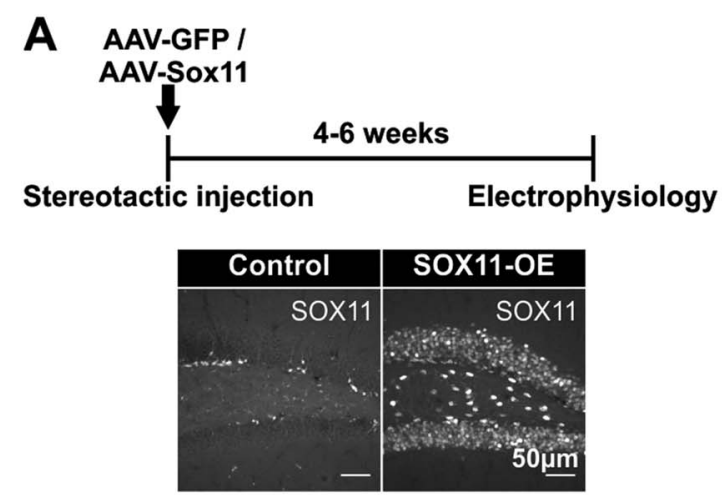

\section{GC excitability upon SOX11-OE:}

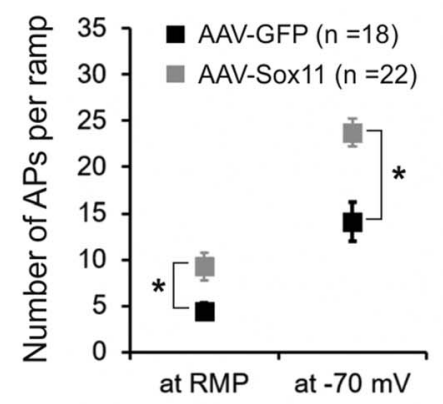

$\mathbf{E}$

\section{Sox 11/4 control mice:}

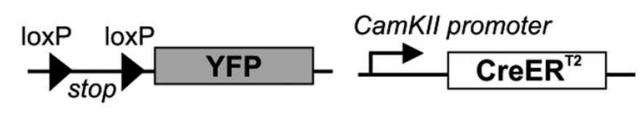

Sox11/4 cKO mice:

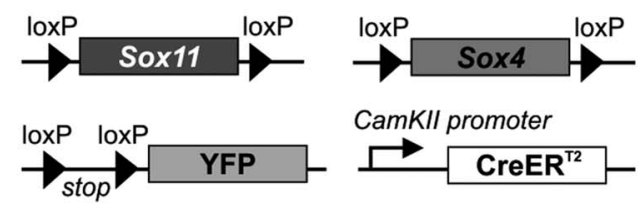

B

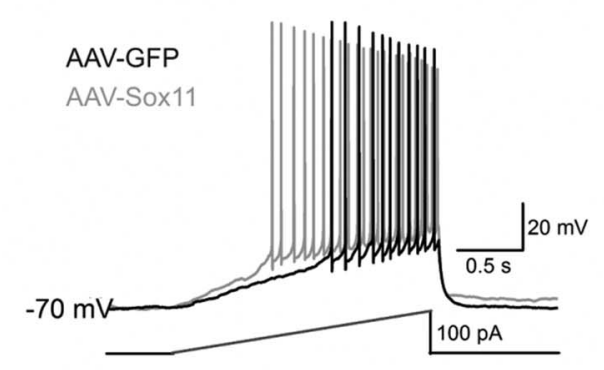

D GC excitability after overnight EE exploration:

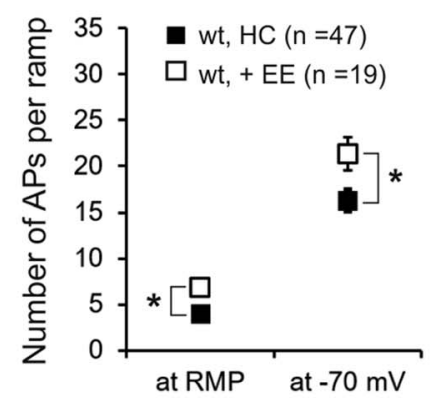

F GC excitability upon KO of Sox11/4:

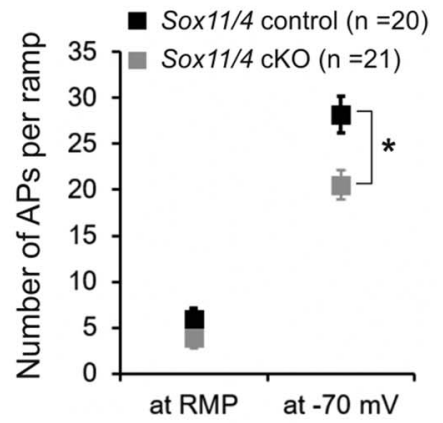

Figure 4. SOX11 modulates GC excitability. (A) Experimental paradigm used for electrophysiological recordings after overexpression of GFP or SOX11 in the DG of C57Bl/6 mice (upper panel). IF staining against SOX11 confirmed efficient overexpression at the time of electrophysiological measurements (lower panel). (B) Superimposed voltage traces from two recordings show earlier and enhanced AP discharges during ramp depolarization in a neuron from AAV-SOX11 slice (gray trace), when compared with neuron from control AAV-GFP slice (black trace). Both cells were held at $-70 \mathrm{mV}$. Note the AAV-SOX11-induced reduction in current threshold to evoke first AP (from 56.4 $\pm 2.8 \mathrm{pA}$ in control cells to $39.5 \pm 1.3 \mathrm{pA}$ in SOX11-OE cells; $P=0.001$ ) (C) Summary of enhanced AP numbers during ramp test in AAV-SOX11 versus AAV-GFP slices. (D) Summary of AP numbers during ramp test in slices from wildtype C57Bl/6 mice with or without overnight exposure to EE. (E) Diagram illustrating transgenic design of Sox11/4 cKO mice (lower panel). Sox11/4 control mice harbor wildtype Sox11 and Sox4 alleles. (F) Summary of AP numbers during ramp test in Sox11/4 cKO versus Sox $11 / 4$ control slices.

ontology-based enrichment analysis showed that upregulated genes were significantly enriched in pathways related to neuron development, as well as in cellular components and molecular functions related to the actin and microtubule cytoskeleton (Fig. 5B). Thus, SOX11-OE significantly induced the expression of genes encoding for different tubulin molecules (Tubb2b, Tubb3, Tubb5, and Tuba1a) and regulators of microtubule stability (Stmn1, Atat1). In addition, a number of genes modifying actin dynamics displayed higher expression in SOX11-OE DG cells (Flna, Filip1, Tmsb10, and Rnd) (Supplementary Table S2). These observations are interesting considering the crucial role of cytoskeletal rearrangement in neuronal plasticity (Gordon-Weeks and Fournier 2014).
Genes downregulated by SOX11 expression were significantly enriched in molecular functions related to potassium ion transport and antiporter activity (Fig. 5C). Several genes involved in the regulation of potassium conductance and chloride transport displayed reduced expression (e.g., Kcnh5, Kcnc2, Kcns2, Glra3, and Slc4a10; Supplementary Table S3). The downregulation of $\mathrm{K}^{+}$ channel subunits upon SOX11-OE was particularly intriguing because the regulation of neuronal excitability is tightly linked to the function of $\mathrm{K}^{+}$channels (Jan and Jan 2012). Moreover, a recent study has shown that a transient, experience-dependent increase in DG granule cell excitability that serves to improve retrieval in a memory task, results from the reduction of an inwardly rectifying $\mathrm{K}^{+}$current mediated by Kir2.1 channels 


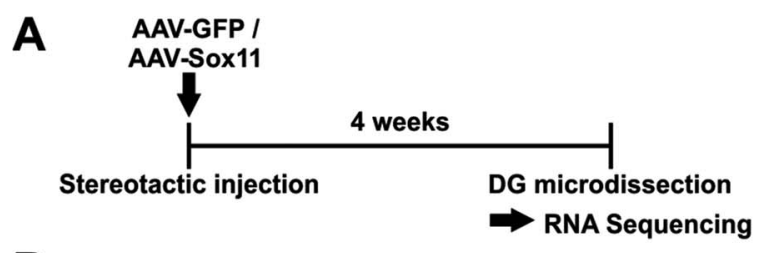

B

\section{Enriched biological processes among up-regulated genes:}

Percentage of genes

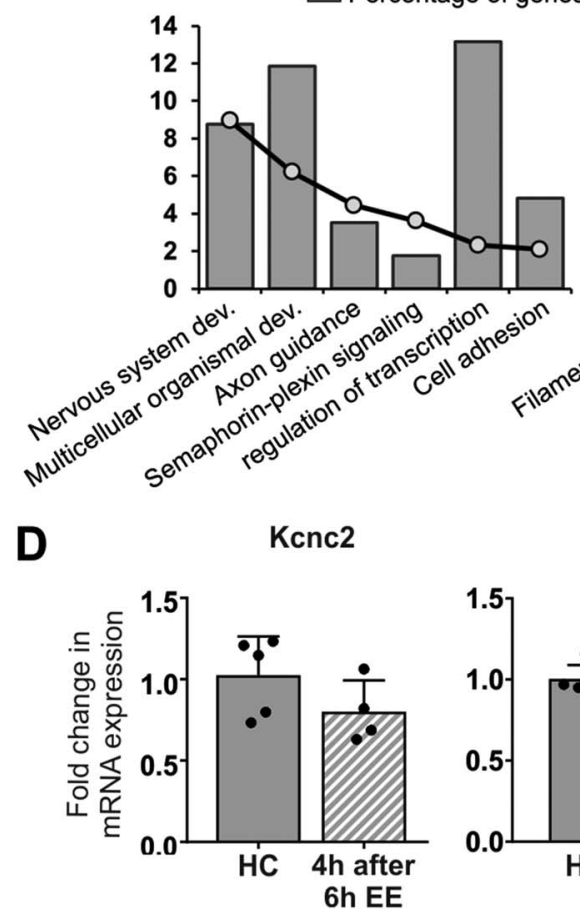

\section{Enriched cellular components among up-regulated genes:}

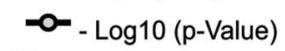

C

\section{Enriched molecular functions among down-regulated genes:}

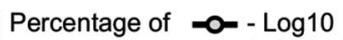
genes

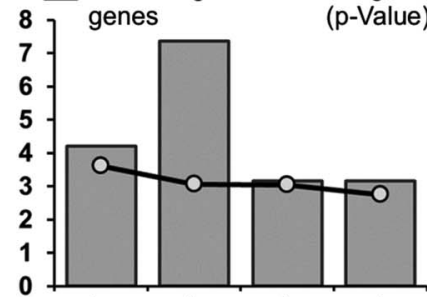

\section{$0 \amalg \square$}
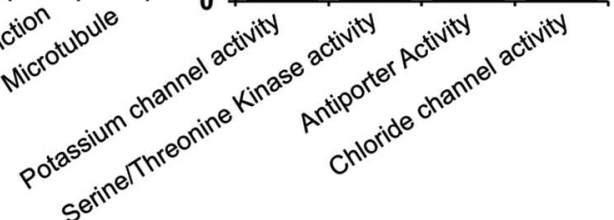

Kenh5

E

Kenc2

Kcnh5
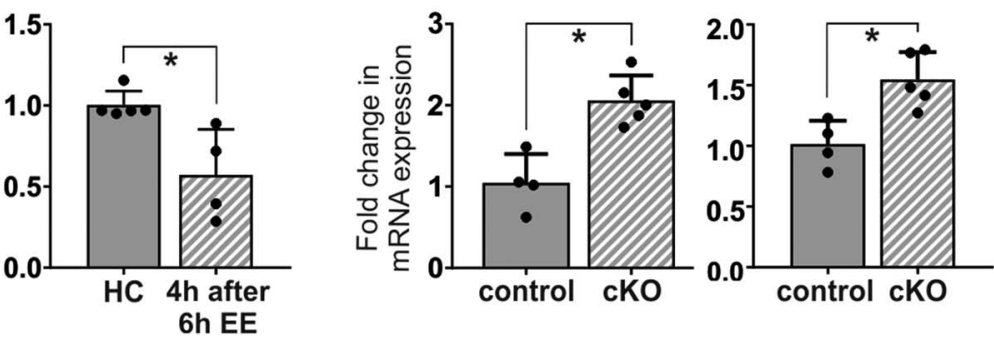

Figure 5. Transcriptome analysis after Sox11-OE reveals changes in cytoskeleton composition and expression pattern of potassium channels. (A) Schematic representation of the paradigm used to generate samples for RNA sequencing. C57Bl/6 mice received bilateral stereotactic injections of AAV-GFP or AAV-Sox11 into the DG. Four weeks after virus injection, DG tissue was dissected and processed for RNA extraction; $n=5$. (B) Gene ontology-based enrichment analysis of upregulated genes after Sox11-OE (Fold change cutoff $\geq 1.5$ ). Graphs show groups of genes with high enrichments scores in order of decreasing-Log10 P-values. Percentage of genes for each group relative to the mapped, upregulated genes is displayed as column, -Log10 P-values for enrichment are represented as line diagram. (C) Enrichment analysis for Gene Ontology molecular functions among downregulated genes after Sox11-OE (Fold change cutoff $\leq 1 / 1.5$ ). (D) $q P C R$ analysis of $\mathrm{K}^{+}$channel subunit genes in wildtype Bl6 mice after EE exploration. DG tissue was dissected from HC mice and from mice $4 \mathrm{~h}$ after $6 \mathrm{~h}$ EE. Expression levels of Kcnc2 and Kcnh5 mRNA were normalized to expression levels in HC mice to calculate the FC of expression. Kcnc2: mean FC \pm SD [1.5 h EE]: $1.34 \pm 0.22 ;[4 \mathrm{~h}$ after EE]: 0.80 $\pm 0.17 ; \mathrm{Kcnh} 5:$ mean FC \pm SD [1.5 h EE]: $0.88 \pm 0.01 ;$ [ $4 \mathrm{~h}$ after EE]: $0.57 \pm 0.24 ; n=4-5$. (E) qPCR analysis of $\mathrm{K}^{+}$channel subunit genes in Sox11/4 cKO mice. DG tissue from Sox11/4 control and Sox11/4 cKO mice was dissected after Tamoxifen treatment and analyzed for expression levels of Kcnc2 and Kcnh5. Both genes display significantly higher expression in Sox11/4 cKO mice. Kcnc2: mean FC \pm SD [Sox11/4 control]: $1.05 \pm 0.35$ versus mean FC \pm SD [Sox11/4 cKO]: $2.06 \pm 0.31 ; P=0.016 ; \mathrm{Kcnh} 5:$ mean FC \pm SD [Sox11/4 control]: $1.01 \pm 0.19$ versus mean $\mathrm{FC} \pm \mathrm{SD}[\mathrm{Sox} 11 / 4 \mathrm{cKO}]: 1.55 \pm 0.23 ; P=0.016 ; n=4$.

(Pignatelli et al. 2019). Thus, we tested whether $\mathrm{K}^{+}$channel subunits are differentially expressed in Sox11/4 cKO mice. We microdissected the DG of Sox $11 / 4$ control and Sox $11 / 4$ cKO mice and quantified the expression levels of $\mathrm{K}^{+}$channel genes using qPCR analysis. Interestingly, two out of three tested $\mathrm{K}^{+}$ channel subunits exhibited significantly higher expression levels in DG tissue from Sox11/4 cKO animals (Fig. 5D), namely Kcnh5 (mean FC \pm SD $[$ Sox11/4 control] $=1.01 \pm 0.19$ vs. mean $\mathrm{FC} \pm \mathrm{SD}[$ Sox11/4 $\mathrm{cKO}]=1.55 \pm 0.23 ; \mathrm{P}=0.016$ ) and Kcnc2 (mean $\mathrm{FC} \pm \mathrm{SD}[$ Sox $11 / 4$ control $]=1.05 \pm 0.35$ vs. mean $\mathrm{FC} \pm \mathrm{SD}[$ Sox $11 / 4$ $\mathrm{cKO}]=2.06 \pm 0.31 ; P=0.016)$. Collectively, these data indicate that Sox11 expression in mature dentate granule neurons can modulate the expression of genes encoding for $\mathrm{K}^{+}$ channel subunits such as Kcnc2 and Kcnh5. Notably, qRT-PCR analysis revealed a trend or significant downregulation of these $\mathrm{K}^{+}$channel subunits in the DG of mice $4 \mathrm{~h}$ post EE compared with the DG of HC-housed mice (Kcnc2: mean FC \pm SD $[\mathrm{HC}]=1.02 \pm 0.24$ vs. mean $\mathrm{FC} \pm \mathrm{SD}[4 \mathrm{~h}$ after $\mathrm{EE}]=0.80 \pm 0.19$; $\mathrm{P}=0.19 ;$ Kcnh5: mean FC $\pm \mathrm{SD}[\mathrm{HC}]=1.00 \pm 0.08$ vs. mean $\mathrm{FC} \pm \mathrm{SD}$ $[4 \mathrm{~h}$ after $\mathrm{EE}]=0.57 \pm 0.28 ; P=0.02$ ) (Fig. $5 E$ ).

\section{Discussion}

Our study reports a new function of the developmental TF Sox11 that appears to bear specific significance for the excitability of mature DG granule cells. We found that high-frequency brain stimulation as well as exploration of a novel environment induced SOX11 expression selectively in the DG. The most remarkable feature of activity-induced Sox11-expression is its 
regional specificity. Neither exploration of a novel environment, which powerfully engages neurons in all hippocampal subfields (Kesner and Rolls 2015), nor the global supraphysiological levels of neuronal activity generated by ECS (Guzowski et al. 1999; French et al. 2001) induced Sox11 in hippocampal subfields other than the DG. Such cell-type specific expression may be the result of specific chromatin marks in regulatory elements of the Sox11 gene. Indeed, the vicinity of the Sox11 gene shows DG-specific open chromatin regions (Su et al. 2017), which might function to define the inducibility of Sox11 in mature DG neurons.

Compared with the timing of classical TF IEGs (e.g., c-fos, Egr1, Nr4a1, Nr4a2, and Nr4a3) induction of Sox11 mRNA and protein expression follows a slower time course and reaches peak expression levels later than $1 \mathrm{~h}$ after stimulation. The delayed activity-dependent expression of Sox11 mRNA and the observation that only $15 \%$ of c-FOS+ neurons expressed SOX11 protein may reflect that the Sox11 gene is regulated by IEG TFs and that Sox11 is part of a second wave of effector genes (Flavell and Greenberg 2008; Sun and Lin 2016). Alternatively, Sox11 may-despite its delayed peak expression—be induced independently of de novo synthesis of IEG TFs and may itself constitute an IEG TF. Slow induction kinetics of an IEG is not without precedent: in fact a number of effector IEGs including Bdnf, Inhba, and Homer1a are induced by neuronal activity with a peak several hours after stimulation (Ghosh et al. 1994; Brakeman et al. 1997; Link et al. 2016).

We provide electrophysiological evidence that beyond its well documented functions in development and repair (Kavyanifar et al. 2018), SOX11 has the potential to function as a modulator of intrinsic excitability in mature neurons. Overexpression of SOX11 resulted in an enhanced spiking frequency of DG granule cells in response to a given stimulus, whereas deletion of Sox11/4 was associated with decreased granule cell responsiveness. We cannot fully exclude that the deletion of Sox4-which in the neurodevelopmental context functions redundantly to Sox11contributed to the observed reduction in excitability. However, there are no indications that mature DG neurons express SOX4 (Mu et al. 2012) or that Sox4 is regulated by neuronal activity [J von Wittgenstein and DC Lie unpublished data; Su et al. (2017); Jaeger et al. (2018)].

How can SOX11 expression modulate the intrinsic excitability of dentate granule cells? We found that SOX11 modulates the expression of genes such as Kcnh5 and Kcnc2, which encode for voltage-dependent $\mathrm{K}^{+}$channels, that is, Kv10.2 (Eag2) and Kv3.2, respectively. It is tempting to link the inverse relationship between SOX11 and $\mathrm{K}^{+}$channel expression to the concomitant changes in granule cell firing. The Sox11dependent modulation of Kv10.2 may be particularly interesting, because expression of Kv10.2 transcripts is sparse and confined to CA3 and DG principal cells (Saganich et al. 2001). While the functions of Kv10.2 are not well understood, it is worth noting that a Kv10.2 mutation has been implicated in drug-resistant epileptic seizures (Yang et al. 2013; Niday and Tzingounis 2018), suggesting an appreciable role of this channel in neuronal excitability, which should be experimentally tested in future studies.

Modulation of intrinsic excitability may represent an important parameter of the granule cell plasticity response. LTP protocols (Bliss and Lomo 1973), mild stimulation paradigms at the medial perforant path (MPP)-DG granule cell synapse (Lopez-Rojas et al. 2016), and engagement of the hippocampal circuitry through environmental exploration (this study) enhance granule cell excitability. Considering the high level of tonic inhibition present in the DG (Engin et al. 2015), adaptation of excitability might facilitate the recruitment of DG granule neurons into memory engrams and the reactivation of DG neurons in response to a previously encountered stimulus (Jaeger et al. 2018). Given the activity-dependent induction of SOX11 expression and the effect of SOX11 expression on excitability, it is tempting to speculate that SOX11 expression participates in the activity-induced modulation of DG granule neuron excitability. It has, however, to be noted that EE-induced SOX11 expression is confined to a subset of granule neurons and thus is not sufficient to explain the change in excitability that was observed in the EE-paradigm across all analyzed granule cells. It will be interesting to determine, whether SOX11 regulates excitability in a distinct subset of DG granule neurons and whether additional activitydependent TFs participate in the modulation DG granule cell excitability.

Our approaches to manipulate SOX11 expression in mature DG neurons were of permanent rather than of transient nature. Thus, while we clearly demonstrate that SOX11 expression potently alters the electrophysiological properties of DG granule cells, it remains to be examined in more detail to which extent the electrophysiological effects reported here mirror the impact of the transient activity-induced SOX11 expression. Sustained Sox11 expression in the DG is, however, not without precedent. Chronic treatment with antidepressants of the serotoninreuptake inhibitor (SSRI) class strongly induces Sox11 mRNA expression in the DG (Sillaber et al. 2008). Notably, SSRI also modulates DG neuron excitability (Stewart and Reid 2000; Kobayashi et al. 2010) in a fashion that is comparable with the modulation induced by SOX11 overexpression. Considering the recent evidence that major effects of the SSRI fluoxetine are mediated by mature DG neurons (Samuels et al. 2015) it will be of major interest to elucidate the importance of SOX11 expression in mediating the actions of antidepressants and to unravel the mechanisms controlling Sox11 expression in mature DG neurons.

\section{Supplementary Material}

Supplementary material can be found at Cerebral Cortex online.

\section{Funding}

German Research Foundation (LI 858/9-1 to D.C.L, INST 410/45-1 FUGG), the Bavarian Research Networks "ForIPS" and "ForINTER," the University Hospital Erlangen (IZKF grants E12 and E21 to D.C.L., and E16 to D.C.L. and A.R.). M.T.W. is a graduate student of the research training group 2162 "Neurodevelopment and Vulnerability of the Central Nervous System" funded by the Deutsche Forschungsgemeinschaft (270949263/DFG GRK2162/1); D.C.L., A.R., and C.A. are principal investigators of the DFG research training group 2162 (DFG GRK2162/1).

\section{Notes}

The authors would like to thank V. Lefebvre and M. Wegner for providing the Sox4 and Sox11 conditional knockout mice, P. Delage and I. Seynat for excellent experimental assistance, and S. Jessberger for valuable comments and suggestions on the manuscript. Conflict of Interest: The authors declare no conflict of interest. 


\section{Author Contributions}

Conceptualization, J.v.W., D.C.L.; Investigation, J.v.W., F.Z., M.T.W., E.-A.B., F.F., I.S., B.M.H., M.J.V.-A., C.J.M.; Formal analysis, J.v.W., F.Z., M.K., D.N.A.; Resources and Funding acquisition, D.C.L.; Writing-Original draft, J.v.W., C.A., D.C.L.; Writing-Review and Editing, J.v.W., C.A., D.C.L.; Supervision: B.K.K., D.N.A., A.R., A.B.E., C.A., D.C.L.

\section{References}

Bhattaram P, Penzo-Mendez A, Sock E, Colmenares C, Kaneko KJ, Vassilev A, Depamphilis ML, Wegner M, Lefebvre V. 2010. Organogenesis relies on SoxC transcription factors for the survival of neural and mesenchymal progenitors. Nat Commun. 1:9.

Bliss TV, Lomo T. 1973. Long-lasting potentiation of synaptic transmission in the dentate area of the anaesthetized rabbit following stimulation of the perforant path. $J$ Physiol. 232:331-356.

Brakeman PR, Lanahan AA, O'Brien R, Roche K, Barnes CA, Huganir RL, Worley PF. 1997. Homer: a protein that selectively binds metabotropic glutamate receptors. Nature. 386:284-288.

Cearley CN, Vandenberghe LH, Parente MK, Carnish ER, Wilson JM, Wolfe JH. 2008. Expanded repertoire of AAV vector serotypes mediate unique patterns of transduction in mouse brain. Mol Ther. 16:1710-1718.

Chen Y, Wang Y, Erturk A, Kallop D, Jiang Z, Weimer RM, Kaminker J, Sheng M. 2014. Activity-induced Nr4a1 regulates spine density and distribution pattern of excitatory synapses in pyramidal neurons. Neuron. 83:431-443.

Cheung M, Abu-Elmagd M, Clevers H, Scotting PJ. 2000. Roles of Sox4 in central nervous system development. Brain Res Mol Brain Res. 79:180-191.

Cheval H, Chagneau C, Levasseur G, Veyrac A, Faucon-Biguet N, Laroche S, Davis S. 2012. Distinctive features of Egr transcription factor regulation and DNA binding activity in CA1 of the hippocampus in synaptic plasticity and consolidation and reconsolidation of fear memory. Hippocampus. 22:631-642.

Deng W, Mayford M, Gage FH. 2013. Selection of distinct populations of dentate granule cells in response to inputs as a mechanism for pattern separation in mice. elife. 2:e00312.

Dobin A, Davis CA, Schlesinger F, Drenkow J, Zaleski C, Jha S, Batut P, Chaisson M, Gingeras TR. 2013. STAR: ultrafast universal RNA-seq aligner. Bioinformatics. 29:15-21.

Engin E, Zarnowska ED, Benke D, Tsvetkov E, Sigal M, Keist R, Bolshakov VY, Pearce RA, Rudolph U. 2015. Tonic inhibitory control of dentate gyrus granule cells by alpha5-containing GABAA receptors reduces memory interference. J Neurosci. 35:13698-13712.

Erdmann G, Schutz G, Berger S. 2007. Inducible gene inactivation in neurons of the adult mouse forebrain. BMC Neurosci. 8:63.

Flavell SW, Greenberg ME. 2008. Signaling mechanisms linking neuronal activity to gene expression and plasticity of the nervous system. Annu Rev Neurosci. 31:563-590.

Foust KD, Nurre E, Montgomery CL, Hernandez A, Chan CM, Kaspar BK. 2009. Intravascular AAV9 preferentially targets neonatal neurons and adult astrocytes. Nat Biotechnol. 27:59-65.

French PJ, O'Connor V, Jones MW, Davis S, Errington ML, Voss K, Truchet B, Wotjak C, Stean T, Doyere V et al. 2001. Subfieldspecific immediate early gene expression associated with hippocampal long-term potentiation in vivo. Eur J Neurosci. 13:968-976.

Ghosh A, Carnahan J, Greenberg ME. 1994. Requirement for BDNF in activity-dependent survival of cortical neurons. Science. 263:1618-1623.

Gordon-Weeks PR, Fournier AE. 2014. Neuronal cytoskeleton in synaptic plasticity and regeneration. J Neurochem. 129:206-212.

Guzowski JF, McNaughton BL, Barnes CA, Worley PF. 1999. Environment-specific expression of the immediate-early gene arc in hippocampal neuronal ensembles. Nat Neurosci. 2:1120-1124.

Hagihara H, Toyama K, Yamasaki N, Miyakawa T. 2009. Dissection of hippocampal dentate gyrus from adult mouse. J Vis Exp.

Haslinger A, Schwarz TJ, Covic M, Lie DC. 2009. Expression of Sox11 in adult neurogenic niches suggests a stage-specific role in adult neurogenesis. Eur J Neurosci. 29:2103-2114.

Jaeger BN, Linker SB, Parylak SL, Barron JJ, Gallina IS, Saavedra CD, Fitzpatrick C, Lim CK, Schafer ST, Lacar B et al. 2018. A novel environment-evoked transcriptional signature predicts reactivity in single dentate granule neurons. Nat Commun. 9:3084.

Jan LY, Jan YN. 2012. Voltage-gated potassium channels and the diversity of electrical signalling. J Physiol. 590:2591-2599.

Kavyanifar A, Turan S, Lie DC. 2018. SoxC transcription factors: multifunctional regulators of neurodevelopment. Cell Tissue Res. 371:91-103.

Kellendonk C, Tronche F, Casanova E, Anlag K, Opherk C, Schutz G. 1999. Inducible site-specific recombination in the brain. J Mol Biol. 285:175-182.

Kesner RP, Rolls ET. 2015. A computational theory of hippocampal function, and tests of the theory: new developments. Neurosci Biobehav Rev. 48:92-147.

Klein RL, Dayton RD, Tatom JB, Diaczynsky CG, Salvatore MF. 2008. Tau expression levels from various adeno-associated virus vector serotypes produce graded neurodegenerative disease states. Eur J Neurosci. 27:1615-1625.

Knierim JJ. 2015. The hippocampus. Curr Biol. 25:R1116-R1121.

Kobayashi K, Ikeda Y, Sakai A, Yamasaki N, Haneda E, Miyakawa T, Suzuki H. 2010. Reversal of hippocampal neuronal maturation by serotonergic antidepressants. Proc Natl Acad Sci U S A. 107:8434-8439.

Liao Y, Smyth GK, Shi W. 2014. featureCounts: an efficient general purpose program for assigning sequence reads to genomic features. Bioinformatics. 30:923-930.

Link AS, Kurinna S, Havlicek S, Lehnert S, Reichel M, Kornhuber J, Winner B, Huth T, Zheng F, Werner S et al. 2016. Kdm6b and Pmepa1 as targets of bioelectrically and behaviorally induced activin A signaling. Mol Neurobiol. 53:4210-4225.

Lopez-Rojas J, Heine M, Kreutz MR. 2016. Plasticity of intrinsic excitability in mature granule cells of the dentate gyrus. Sci Rep. 6:21615.

Lopez-Rojas J, Kreutz MR. 2016. Mature granule cells of the dentate gyrus-passive bystanders or principal performers in hippocampal function? Neurosci Biobehav Rev. 64: 167-174.

Love MI, Huber W, Anders S. 2014. Moderated estimation of fold change and dispersion for RNA-seq data with DESeq2. Genome Biol. 15:550.

Ma DK, Jang MH, Guo JU, Kitabatake Y, Chang ML, PowAnpongkul N, Flavell RA, Lu B, Ming GL, Song H. 2009. Neuronal activity-induced Gadd45b promotes epigenetic 
DNA demethylation and adult neurogenesis. Science. 323:1074-1077.

Martin M. 2011. Cutadapt removes adapter sequences from highthroughput sequencing reads. EMBnet.journal. 17:10-12.

McNulty SE, Barrett RM, Vogel-Ciernia A, Malvaez M, Hernandez N, Davatolhagh MF, Matheos DP, Schiffman A, Wood MA. 2012. Differential roles for Nr4a1 and Nr4a2 in object location vs. object recognition long-term memory. Learn Mem. 19:588-592.

Minatohara K, Akiyoshi M, Okuno H. 2015. Role of immediateearly genes in synaptic plasticity and neuronal ensembles underlying the memory trace. Front Mol Neurosci. 8:78.

$\mathrm{Mu}$ L, Berti L, Masserdotti G, Covic M, Michaelidis TM, Doberauer K, Merz K, Rehfeld F, Haslinger A, Wegner M et al. 2012. SoxC transcription factors are required for neuronal differentiation in adult hippocampal neurogenesis.J Neurosci. 32:3067-3080.

Neunuebel JP, Knierim JJ. 2012. Spatial firing correlates of physiologically distinct cell types of the rat dentate gyrus. J Neurosci. 32:3848-3858.

Nicoll RA, Schmitz D. 2005. Synaptic plasticity at hippocampal mossy fibre synapses. Nat Reu Neurosci. 6:863-876.

Niday Z, Tzingounis AV. 2018. Potassium channel gain of function in epilepsy: an unresolved paradox. Neuroscientist. 24:368-380.

Pathan M, Keerthikumar S, Ang CS, Gangoda L, Quek CY, Williamson NA, Mouradov D, Sieber OM, Simpson RJ, Salim A et al. 2015. FunRich: an open access standalone functional enrichment and interaction network analysis tool. Proteomics. 15:2597-2601.

Penzo-Mendez A, Dy P, Pallavi B, Lefebvre V. 2007. Generation of mice harboring a Sox 4 conditional null allele. Genesis. 45:776-780.

Pignatelli M, Ryan TJ, Roy DS, Lovett C, Smith LM, Muralidhar S, Tonegawa S. 2019. Engram cell excitability state determines the efficacy of memory retrieval. Neuron. 101(274-284):e275.

Potzner MR, Tsarovina K, Binder E, Penzo-Mendez A, Lefebvre V, Rohrer H, Wegner M, Sock E. 2010. Sequential requirement of Sox4 and Sox11 during development of the sympathetic nervous system. Development. 137:775-784.

Saganich MJ, Machado E, Rudy B. 2001. Differential expression of genes encoding subthreshold-operating voltage-gated $\mathrm{K}^{+}$ channels in brain. J Neurosci Off J Soc Neurosci. 21:4609-4624.

Samuels BA, Anacker C, Hu A, Levinstein MR, Pickenhagen A, Tsetsenis T, Madronal N, Donaldson ZR, Drew LJ, Dranovsky A et al. 2015. 5-HT1A receptors on mature dentate gyrus granule cells are critical for the antidepressant response. Nat Neurosci. 18:1606-1616.

Schindelin J, Arganda-Carreras I, Frise E, Kaynig V, Longair M, Pietzsch T, Preibisch S, Rueden C, Saalfeld S, Schmid B et al. 2012. Fiji: an open-source platform for biological-image analysis. Nat Methods. 9:676-682.

Schmidt B, Marrone DF, Markus EJ. 2012. Disambiguating the similar: the dentate gyrus and pattern separation. Behav Brain Res. 226:56-65.
Schmidt-Hieber C, Jonas P, Bischofberger J. 2004. Enhanced synaptic plasticity in newly generated granule cells of the adult hippocampus. Nature. 429:184-187.

Sheng M, Greenberg ME. 1990. The regulation and function of c-fos and other immediate early genes in the nervous system. Neuron. 4:477-485.

Sillaber I, Panhuysen M, Henniger MS, Ohl F, Kuhne C, Putz B, Pohl T, Deussing JM, Paez-Pereda M, Holsboer F. 2008. Profiling of behavioral changes and hippocampal gene expression in mice chronically treated with the SSRI paroxetine. Psychopharmacology. 200:557-572.

Sloviter RS. 1989. Calcium-binding protein (calbindin-D28k) and parvalbumin immunocytochemistry: localization in the rat hippocampus with specific reference to the selective vulnerability of hippocampal neurons to seizure activity. J Comp Neurol. 280:183-196.

Soule J, Penke Z, Kanhema T, Alme MN, Laroche S, Bramham CR. 2008. Object-place recognition learning triggers rapid induction of plasticity-related immediate early genes and synaptic proteins in the rat dentate gyrus. Neural Plast. 2008: 269097.

Spiegel I, Mardinly AR, Gabel HW, Bazinet JE, Couch CH, Tzeng CP, Harmin DA, Greenberg ME. 2014. Npas4 regulates excitatoryinhibitory balance within neural circuits through cell-typespecific gene programs. Cell. 157:1216-1229.

Srinivas S, Watanabe T, Lin CS, William CM, Tanabe Y, Jessell TM, Costantini F. 2001. Cre reporter strains produced by targeted insertion of EYFP and ECFP into the ROSA26 locus. BMC Dev Biol. 1:4.

Stewart CA, Reid IC. 2000. Repeated ECS and fluoxetine administration have equivalent effects on hippocampal synaptic plasticity. Psychopharmacology. 148:217-223.

Su Y, Shin J, Zhong C, Wang S, Roychowdhury P, Lim J, Kim D, Ming GL, Song H. 2017. Neuronal activity modifies the chromatin accessibility landscape in the adult brain. Nat Neurosci. 20:476-483.

Sun W, Park KW, Choe J, Rhyu IJ, Kim IH, Park SK, Choi B, Choi SH, Park SH, Kim H. 2005. Identification of novel electroconvulsive shock-induced and activity-dependent genes in the rat brain. Biochem Biophys Res Commun. 327:848-856.

Sun X, Lin Y. 2016. Npas4: linking neuronal activity to memory. Trends Neurosci. 39:264-275.

R Core Team. R: A Language and Environment for Statistical Computing; 2015. R Foundation for Statistical Computing. Available from: https://www.R-project.org/.

Yang Y, Vasylyev DV, Dib-Hajj F, Veeramah KR, Hammer MF, Dib-Hajj SD, Waxman SG. 2013. Multistate structural modeling and voltage-clamp analysis of epilepsy/autism mutation Kv10.2-R327H demonstrate the role of this residue in stabilizing the channel closed state. J Neurosci Off J Soc Neurosci. 33:16586-16593.

Zheng F, Wess J, Alzheimer C. 2012. M2 muscarinic acetylcholine receptors regulate long-term potentiation at hippocampal CA3 pyramidal cell synapses in an input-specific fashion. $J$ Neurophysiol. 108:91-100. 